\title{
Immunogenicity of Alternative Dosing Schedules for HPV Vaccines among Adolescent Girls and Young Women: A Systematic Review and Meta-Analysis
}

\author{
Andrew M. Secor 1,2,*(D), Matthew Driver ${ }^{1,3}$, Brenda Kharono ${ }^{1,2}$, Dianna Hergott 1,3 ${ }^{\mathbb{D}}$, Gui Liu ${ }^{3}$, \\ Ruanne V. Barnabas $2,3,4$, Peter Dull ${ }^{5}$, Stephen E. Hawes ${ }^{1,2,3}$ and Paul K. Drain 1,2,4 \\ 1 START Center, University of Washington, Seattle, WA 98195, USA; mpdriver@uw.edu (M.D.); \\ bkharono@uw.edu (B.K.); dhergott@uw.edu (D.H.); hawes@uw.edu (S.E.H.); pkdrain@uw.edu (P.K.D.) \\ 2 Department of Global Health, University of Washington, Seattle, WA 98195, USA; rbarnaba@uw.edu \\ 3 Department of Epidemiology, University of Washington, Seattle, WA 98195, USA; guiliu@uw.edu \\ 4 Department of Medicine, University of Washington, Seattle, WA 98195, USA \\ 5 Bill and Melinda Gates Foundation, Seattle, WA 98109, USA; peter.dull@gatesfoundation.org \\ * Correspondence: amsecor@gmail.com; Tel.: +1-(603)-491-9465
}

Received: 18 September 2020; Accepted: 13 October 2020; Published: 20 October 2020

\begin{abstract}
Alternative dosing schedules for licensed human papilloma virus (HPV) vaccines, particularly single dose and extended intervals between doses ( $>12$ months), are being considered to address vaccine shortages and improve operational flexibility. We searched PUBMED/MEDLINE for publications reporting immunogenicity data following administration of one of the licensed HPV vaccines (2vHPV, $4 \mathrm{vHPV}$, and $9 \mathrm{vHPV})$ to females aged 9-26 years. We conducted non-inferiority analyses comparing alternative to standard schedules using mixed effects meta-regression controlling for baseline HPV status and disaggregated by vaccine, subtype, time point, and age group (9-14 and 15-26 years). Non-inferiority was defined as the lower bound of the $95 \%$ confidence interval (CI) for the geometric mean titer (GMT) ratio being greater than 0.5. Our search returned 2464 studies, of which 23 were included in data analyses. When evaluated against standard schedules, although robust immunogenicity was demonstrated across all multi-dose groups, non-inferiority of extended interval dosing was mixed across vaccines, subtypes, and time points. Single dose did not meet the criteria for non-inferiority in any comparisons. Sparse data limited the number of possible comparisons, and further research is warranted.
\end{abstract}

Keywords: HPV; vaccines; immunogenicity; alternative dosing schedules; meta-analysis

\section{Introduction}

Cervical cancer is one of the most common cancers among women [1]. There are an estimated 570,000 incident cases per year, and in 2018 an estimated 311,000 women died from the disease [2]. Human papilloma virus (HPV) is the leading cause of cervical cancer, with the majority of cases attributable to subtypes 16 and 18 [3]. HPV is one of the most common sexually transmitted infections, with a lifetime risk of infection of 75-80\% among sexually active individuals [4] and an estimated global prevalence of 11-12\% [5]. Higher rates of both HPV infection and cervical cancer have been seen in low- and middle-income (LMIC) countries [2,5], and it is estimated that LMICs account for $90 \%$ of cervical cancer deaths [6].

Three HPV vaccines licensed by the Food and Drug Administration (FDA) and European Medicines Agency (EMA) were approved for a three-dose schedule (0,1 or 2, 6 months). After several clinical trials demonstrated non-inferiority in non-immunocompromised individuals between ages 9 and 14 , the WHO recommended a two-dose schedule $(0,6$ months for the quadrivalent and 
nonavalent vaccines, and $0,5-13$ months for the bivalent vaccine) [7]. In response to global vaccine shortages, and to promote greater vaccination rates by decreasing barriers to schedule completion and costs of implementation of vaccination programs, other alternative dosing schedules are now being explored [8-10]. Specifically, extended interval dosing, defined here as at least 12 months between first and second dose, and single dosing are being investigated as ways to increase vaccination rates, particularly in LMICs. Extended interval dosing could increase schedule completion by allowing more flexibility for follow-up visits, and a single dose schedule would allow for higher coverage with reduced costs, which is particularly important given the substantially higher cost of HPV vaccines as compared to other vaccines.

Current single dose data are limited to post-hoc analyses, and there are limited extended interval dosing data. On-going randomized controlled trials (RCTs) will deliver immunogenicity and efficacy data on single dose in the coming years, with the novel Cecolin vaccine already showing promising results [9]. The aim of this study was to systematically review and compare the existing data on the immunogenicity of extended interval and single dose schedules versus standard dose schedules in a non-inferiority meta-analysis, in order to detail and assess the current evidence base of these alternative dosing schedules.

\section{Materials and Methods}

\subsection{Literature Search and Study Selection}

In accordance with PRISMA guidelines [11], we conducted a systematic review to identify post-vaccination immunogenicity data for HPV vaccines among human participants. We searched the PUBMED/MEDLINE database for English-language publications indexed through 29 April 2019. Abstracts and full-text publications were screened independently using Excel and Covidence software (Covidence, Melbourne, Australia). All publications were screened by at least two reviewers, and conflicts were resolved via a third-party reviewer.

Inclusion criteria were: human studies reporting geometric mean titers (GMT) for HPV subtypes 16 and 18 of adolescent girls and young women aged 9-26 years following vaccination with one of the three licensed HPV vaccines using either standard, extended, or single dosing schedules via intramuscular administration. Studies meeting those criteria were excluded if they reported results in units without published conversion factors for international units. For studies in which GMT estimates or $95 \%$ confidence intervals were not explicitly reported in the text of the publication, relevant data were requested from the corresponding authors.

\subsection{Data Extraction}

Two reviewers extracted and verified the data, and a third reviewer resolved any conflicts. We abstracted study metadata, including: title, author, publication year, PMID number, NCT number, assay type, vaccine type and manufacturer, HPV type tested or reported (i.e., HPV subtype 16 or 18), sex, age, sample size, baseline HPV status, country, HIV status, presence of other comorbidities, number of doses received before antibody testing, dosing schedule, time between receipt of first vaccine and antibody testing, GMT point estimates, $95 \%$ confidence intervals, and units.

We extracted GMTs reported at one month post-last dose, 36 months post-first dose, and 72 months post-first dose in order to evaluate short-term, mid-term, and long-term immunogenicity, respectively. Data reported within 12 months of the mid-term time point or within 24 months of the long-term time point were collected if 36-month and 72-month data were not available, respectively; for example, if a study reported GMTs at month 30 but not month 36, the month 30 GMT would be extracted for the mid-term time point.

All comparisons and pooled estimates were calculated using international units (IU/mL). Conversion rates for $\mathrm{mMU} / \mathrm{mL}$ and $\mathrm{EU} / \mathrm{mL}$ to $\mathrm{IU} / \mathrm{mL}$ were obtained from published literature $[12,13]$. 


\subsection{Definitions}

\subsubsection{Vaccines}

There are currently three HPV vaccines licensed by the Food and Drug Administration (FDA) and European Medicines Agency (EMA): Bivalent (HPV 16/18, Cervarix, GSK), quadrivalent (HPV 6/11/16/18, Gardasil-4, Merck), and nonavalent (HPV 6/11/16/18/31/33/45/52/58, Gardasil-9, Merck), all of which have been shown to be highly efficacious [7,14-19].

\subsubsection{Age}

Adolescent girls and young women aged 9-26 years were included in the study. Ages were aggregated in the following ranges to match current HPV vaccine policy and in response to differential immunogenicity by age group: 9-14 and 15-26. Studies with reported data aggregated across our age groups (e.g., ages 10-18) were excluded, with one exception: Gilca 2019 [20], a key source of single and extended dose data, which reported aggregated results for ages 13-18. As prior research shows that younger groups tend to have higher immunogenicity [21], these data were coded as 9-14 for a more conservative estimate of immune response in alternative schedules.

\subsubsection{Dose}

Extended dose was defined as at least 12 months between doses. Standard dose was defined by current HPV vaccination policy: 2 doses at months 0 and 6, or 3 doses at months 0,1 or 2, and 6 [7].

\subsubsection{Analysis}

GMT ratios and confidence intervals (CIs) comparing alternative to standard schedules were calculated using mixed effects meta-regression controlling for baseline HPV status and disaggregated by vaccine, HPV subtype, time point, and age group (9-14 and 15-26 years). Due to a lack of an established correlate of protection for HPV vaccine immunogenicity, we conducted a non-inferiority analysis to compare alternative to standard dosing schedules. Non-inferiority was assessed by estimating the ratio of pooled GMTs comparing extended interval or single dose to standard schedules at the same time point, with non-inferiority defined as the lower bound of the 95\% CI for the GMT ratio being greater than 0.5 [22]. All analyses were conducted in R (version 3.6.1, R Foundation for Statistical Computing, Vienna, Austria).

\section{Results}

\subsection{Study Selection}

We identified 2464 studies using the search criteria (Figure 1). After removing duplicates and screening titles and abstracts, 367 studies were included for full-text review. Of these, 344 were excluded from the present analysis. The most common reasons for exclusion were lack of relevant immunogenicity data (107), duplicate or previously reported data (54), using an assay without a published conversion factor for international units (17), or trials using a non-licensed vaccine (16). Of note, three single dose and/or extended interval studies were excluded from the meta-analysis, two due to using an assay without a published conversion factor for international units $[23,24]$, and one due to lack of available GMT data [25]. Standard dose studies were excluded if there were no available alternative schedule comparison data.

In total, 23 studies were included in the present analysis; four contributed to extended interval data only [26-29], two to single dose data only [10,30], one study contributed to both [20], and 16 to comparator data only $[17,19,21,22,31-42]$. 


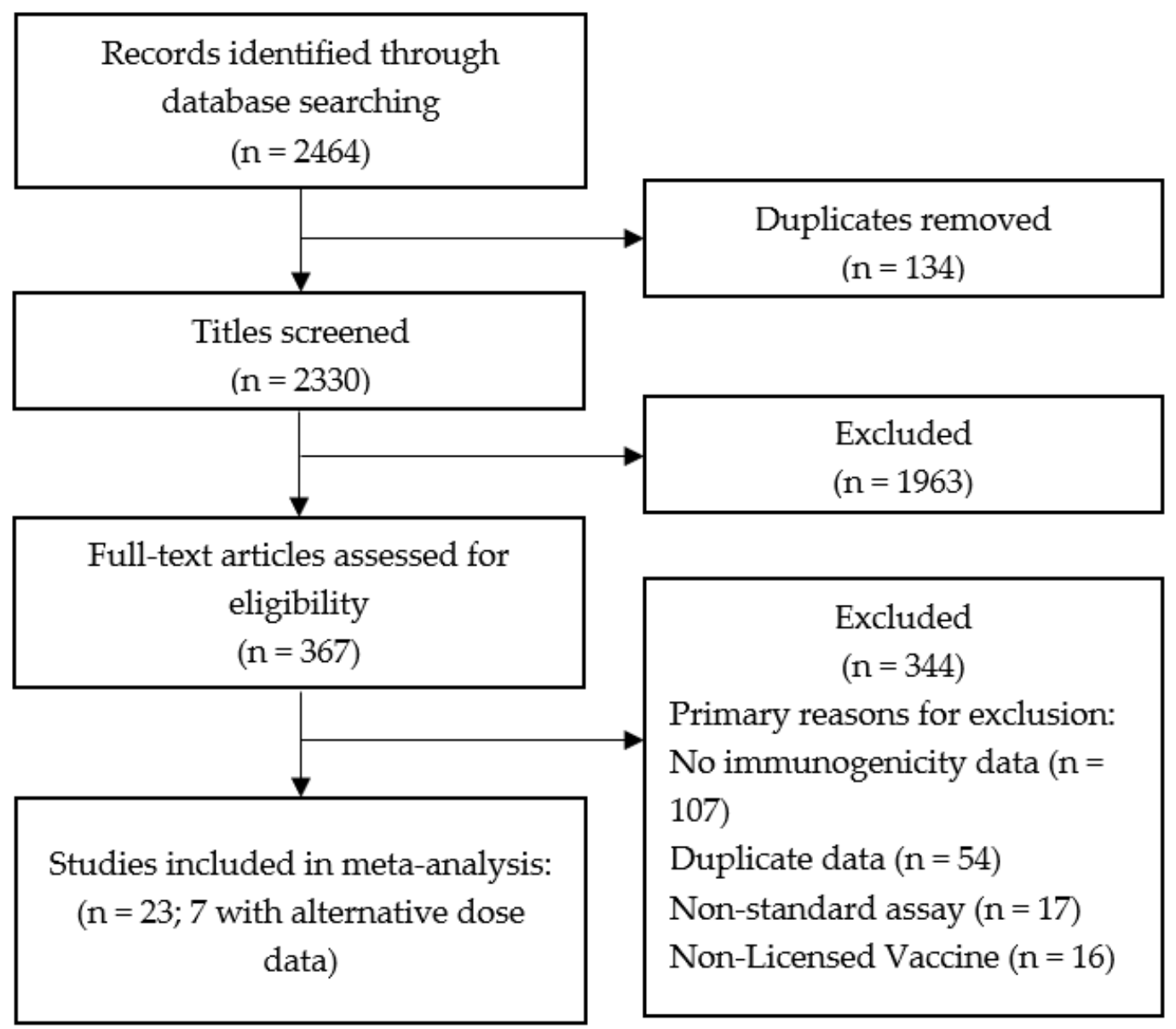

Figure 1. PRISMA diagram.

\subsection{Study Characteristics}

Included alternative dose studies are detailed in Table 1. All three licensed vaccines were included in the analysis. Extended interval had data for all three time points, while single dose only had mid(36 months) and long-term (72 months) data. Included studies were conducted in North America (13), South America (2), Europe (9), Africa (3), and Asia (10). Seventeen of the included studies were randomized control trials, five were non-randomized trials or cohort studies, and one was a cross-sectional study. Sample sizes ranged from 18 to 2635.

Table 1. Included single dose and extended interval studies.

\begin{tabular}{|c|c|c|c|c|c|c|c|c|c|}
\hline \multirow{2}{*}{ Author, Year } & \multicolumn{2}{|c|}{ Alternative Schedules } & \multirow{2}{*}{$\begin{array}{l}\text { Dose Schedules } \\
\text { (Months) }\end{array}$} & \multirow{2}{*}{ Study Design * } & \multicolumn{2}{|c|}{ Age Range(s) } & \multirow{2}{*}{$\mathbf{N}^{* *}$} & \multirow{2}{*}{ Vaccine(s) } & \multirow{2}{*}{ Region(s) } \\
\hline & Extended & Single & & & 9-14 & $15-26$ & & & \\
\hline Gilca 2019 [20] & $x$ & $\mathrm{x}$ & $\begin{array}{c}\text { Single; }(0,36-48) ; \\
(0,60-72) ;(0,84-96)\end{array}$ & NRS & $x$ & & 31 & $\begin{array}{l}\text { Quadrivalent, } \\
\text { nonavalent }\end{array}$ & N. America \\
\hline LaMontagne 2013 [27] & $x$ & & $(0,2,6) ;(0,12,24)$ & RCT & $x$ & & 223 & Quadrivalent & Asia \\
\hline Puthanakit 2016 [29] & $\mathrm{x}$ & & $(0,1,6) ;(0,6) ;(0,12)$ & $\mathrm{RCT}$ & $\mathrm{x}$ & $x$ & 1195 & Bivalent & $\begin{array}{l}\text { Asia, Europe, } \\
\text { N. America }\end{array}$ \\
\hline Safaeian 2018 [10] & & $\mathrm{x}$ & Single; $(0,1,6) ;(0,6)$ & RCT & & $\mathrm{x}$ & 330 & Bivalent & N. America \\
\hline
\end{tabular}

${ }^{*} \mathrm{RCT}=$ Randomized control trial; NRS $=$ Non-randomized control trial. ${ }^{* *}$ Sample size for data included in analysis. 


\subsection{Extended Interval}

Five studies contributed to the extended interval data and 17 to the comparison data, including four contributing to both. Extended interval data were only available for the 9-14 age range for all three vaccines. The bivalent vaccine had data for one month and 36 months post-first dose, the quadrivalent vaccine had data for all three time points, and the nonavalent vaccine for only one month post-last dose. Figure 2 shows comparisons in pooled GMT, and Figure 3 shows GMT ratios and the non-inferiority analysis.

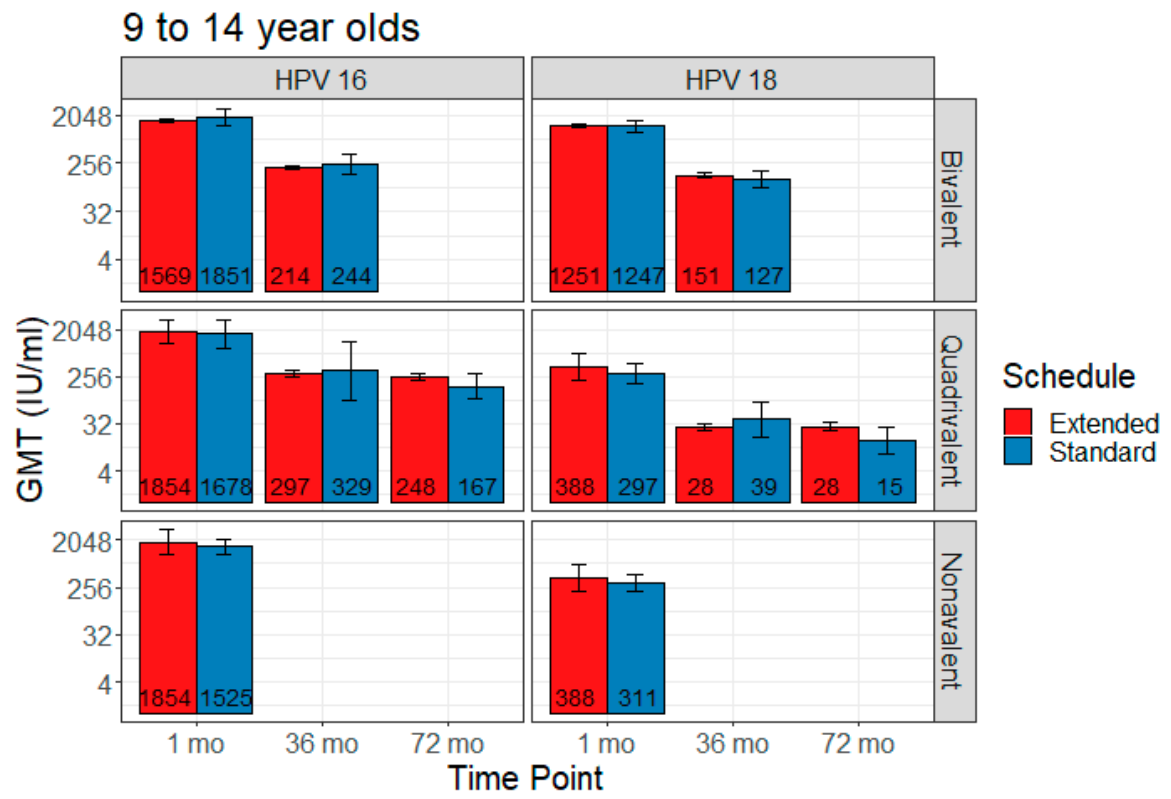

Figure 2. Comparison of pooled geometric mean titer (GMT) for extended interval versus standard schedule (with $95 \%$ CI error bars).

9 to 14 years

HPV type $\mathrm{N}$ (standard) N (extended) GMT ratio $(95 \% \mathrm{Cl}$

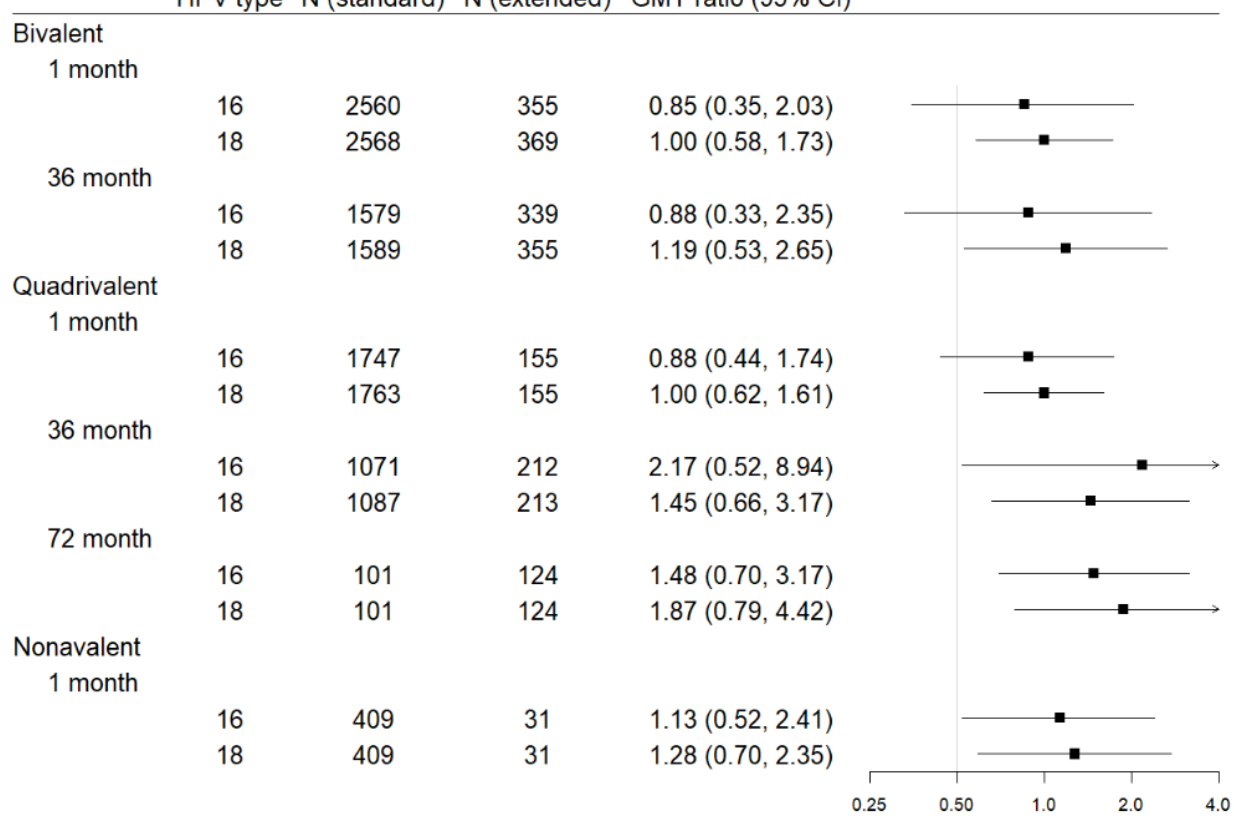

Figure 3. Forest plot of GMT ratio of extended interval versus standard schedule (with 0.5 indicating the non-inferiority cut-point-i.e., those with lower bounds greater than 0.5 are considered to meet non-inferiority criteria), by vaccine, human papilloma virus (HPV) subtype, time point, and age group. 


\subsubsection{Bivalent}

Two studies reported bivalent vaccine extended dose data: Puthanakit 2016 (one month) [29] and Huang 2017 (36 months) [26]. Extended interval demonstrated non-inferiority for the bivalent vaccine for HPV 18 at one month post-last dose and 36 months post-first dose. Non-inferiority was not met for HPV 16 at either of those time points in this vaccine.

HPV 16 GMT estimates for standard vs. extended dose were $1851 \mathrm{IU} / \mathrm{mL}$ (95\% CI 1269-2699) vs. $1569 \mathrm{IU} / \mathrm{mL}$ (95\% CI 712-3455) at one month post-last dose, and $244 \mathrm{IU} / \mathrm{mL}$ (95\% CI 155-383) vs. $214 \mathrm{IU} / \mathrm{mL}$ (95\% CI 89-512) at 36 months. HPV 18 GMT estimates for standard vs. extended dose were $1247 \mathrm{IU} / \mathrm{mL}$ (95\% CI 973-1599) vs. $1251 \mathrm{IU} / \mathrm{mL}$ (95\% CI 773-2026) at one month post-last dose, and $127 \mathrm{IU} / \mathrm{mL}$ (95\% CI 88-185) vs. $151 \mathrm{IU} / \mathrm{mL}$ (95\% CI 74-308) at 36 months.

\subsubsection{Quadrivalent}

Three studies reported quadrivalent vaccine extended dose data: Gilca 2019 (one month) [20], LaMontagne 2013 (one month and 72 months) [27], and Neuzil 2011 (36 months) [28]. Extended interval demonstrated non-inferiority in the quadrivalent vaccine for HPV 18 at all time points and for HPV 16 at 36 months and 72 months. Non-inferiority was not met for HPV 16 at one month post-last dose.

HPV 16 GMT estimates for standard vs. extended dose were $1678 \mathrm{IU} / \mathrm{mL}$ (95\% CI 882-3193) vs. $1474 \mathrm{IU} / \mathrm{mL}(95 \%$ CI 781-2779) at one month post-last dose, $329 \mathrm{IU} / \mathrm{mL}$ (95\% CI 91-1189) vs. $297 \mathrm{IU} / \mathrm{mL}$ (95\% CI 82-1080) at 36 months, and $167 \mathrm{IU} / \mathrm{mL}$ (95\% CI 97-286) vs. $248 \mathrm{IU} / \mathrm{mL}$ (95\% CI 146-422) at 72 months. HPV 18 GMT estimates for standard vs. extended dose were $297 \mathrm{IU} / \mathrm{mL}$ (95\% CI 189-467) vs. $297 \mathrm{IU} / \mathrm{mL}$ (95\% CI 178-496) at one month post-last dose, $39 \mathrm{IU} / \mathrm{mL}(95 \%$ CI 18-84) vs. $28 \mathrm{IU} / \mathrm{mL}$ (95\% CI 14-57) at 36 months, and $15 \mathrm{IU} / \mathrm{mL}$ (95\% CI 8-28) vs. $28 \mathrm{IU} / \mathrm{mL}(95 \%$ CI 16-52) at 72 months.

\subsubsection{Nonavalent}

One study reported nonavalent vaccine extended dose data: Gilca 2019 (one month) [20]. Extended interval was non-inferior to the standard dose schedule for both HPV 16 and HPV 18 at one month post-last dose.

At one month post-last dose, HPV 16 GMT estimates for standard vs. extended dose were $1525 \mathrm{IU} / \mathrm{mL}$ (95\% CI 1081-2152) vs. $1717 \mathrm{IU} / \mathrm{mL}$ (95\% CI 869-3392), and HPV 18 GMT estimates were $311 \mathrm{IU} / \mathrm{mL}$ (95\% CI $215-451)$ vs. 396 IU/mL (95\% CI 201-781).

\subsection{Single Dose}

Three studies contributed to the single dose data and 14 to the comparison data, including two contributing to both. Single dose data were only available for the bivalent and quadrivalent vaccines, both of which had data at 36 months and 72 months post-first dose. Quadrivalent vaccine data were limited to the 9-14 age range, while bivalent vaccine data were available for both 9-14 and 15-26 ranges (although not at all time points). Figure 4 shows comparisons in pooled GMT, and Figure 5 shows GMT ratios and the non-inferiority analysis. Non-inferiority of single dose compared to standard dose was not demonstrated for either vaccine for both subtypes in relation to all time points and age groups compared. 


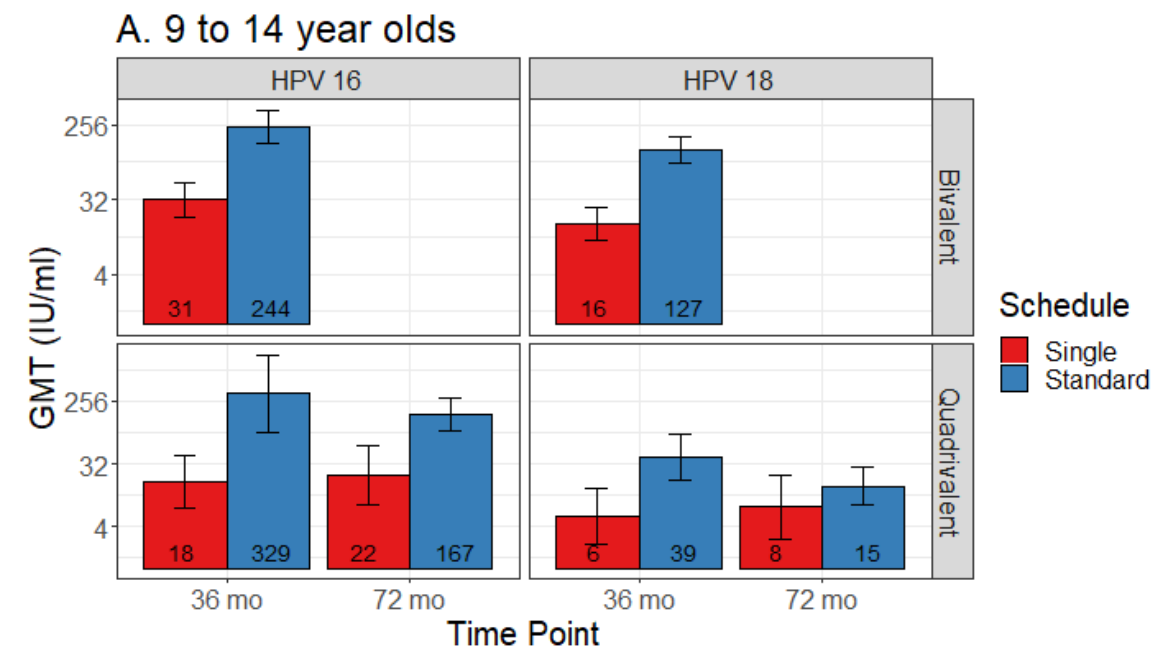

\section{B. 15 to 26 year olds}

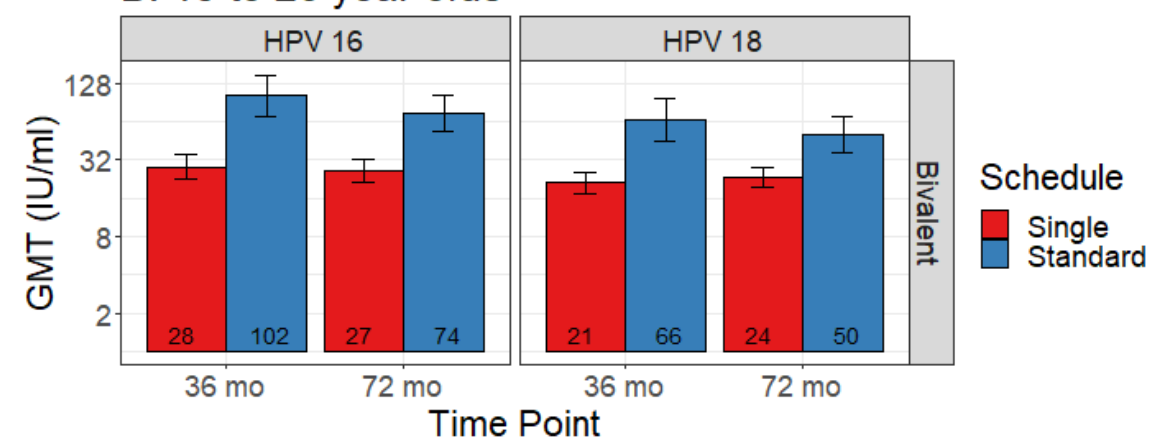

Figure 4. Comparison of geometric mean titers (GMT) for single dose versus standard schedule (with 95\% CI error bars) among (A) 9 to 14 year olds and (B) 15 to 26 year olds.

\section{A. 9 to 14 year olds}

HPV type $N$ (standard) $N$ (single) GMT ratio $(95 \% \mathrm{Cl})$

\section{Bivalent}

36 month

$\begin{array}{llll}16 & 1579 & 36 & 0.14(0.03,0.69) \\ 18 & 1589 & 36 & 0.22(0.06,0.87)\end{array}$

Quadrivalent

36 month

$\begin{array}{llll}16 & 1071 & 11 & 0.05(0.01,0.47) \\ 18 & 1087 & 11 & 0.14(0.03,0.72)\end{array}$

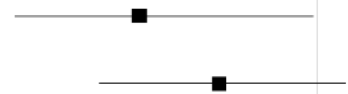

72 month

$\begin{array}{llll}16 & 101 & 11 & 0.13(0.03,0.58) \\ 18 & 101 & 11 & 0.50(0.11,2.40)\end{array}$

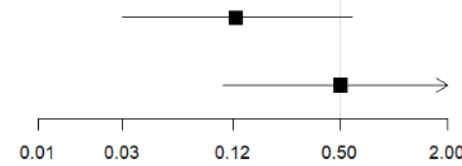

Figure 5. Cont. 
B. 15 to 26 year olds

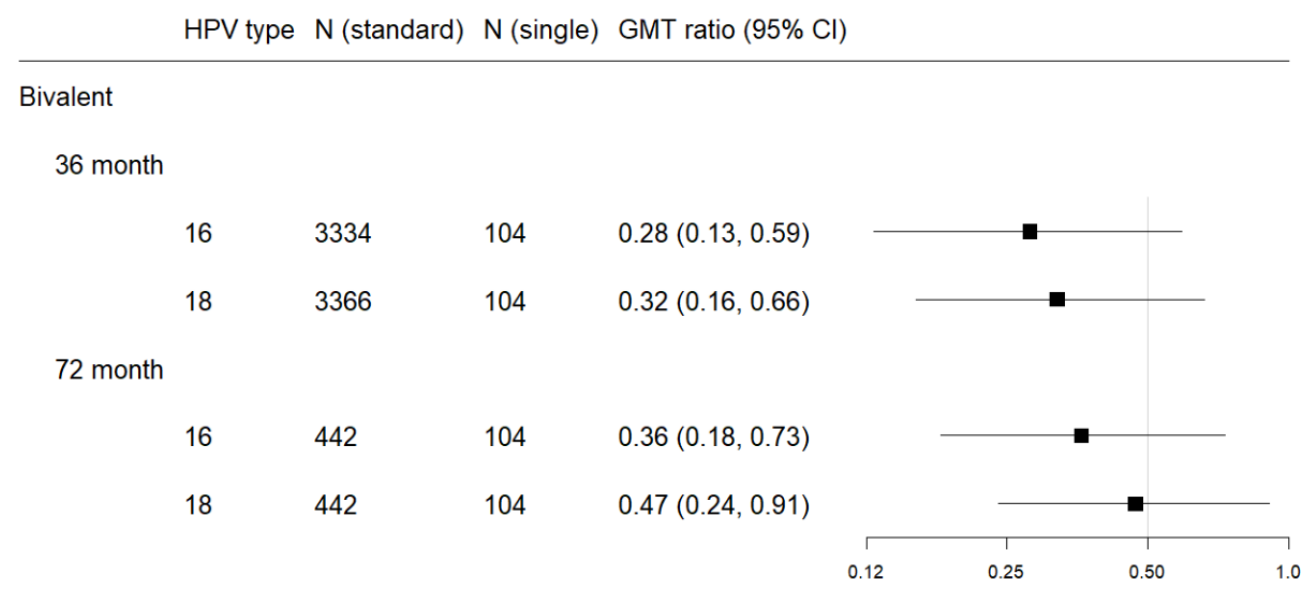

Figure 5. Forest plot of GMT ratio of single dose versus standard schedule (with 0.5 indicating the non-inferiority cut-point-i.e., those with lower bounds greater than 0.5 are considered to meet non-inferiority criteria), by vaccine, HPV subtype, and time point among (A) 9 to 14 year olds and (B) 15 to 26 year olds.

\subsubsection{Bivalent}

Two studies reported bivalent vaccine single dose data: LaMontagne 2014 (36 months, 9-14 years) [30] and Safaeian 2018 (36- and 72-month data, 15-26 years) [10]. Non-inferiority was not met for either HPV sub-type for any of the age groups or time points.

For the 9-14 year old group, at 36 months post-first dose, HPV 16 GMT estimates for standard vs. single dose were $244 \mathrm{IU} / \mathrm{mL}$ (95\% CI 155-383) vs. $31 \mathrm{IU} / \mathrm{mL}$ (95\% CI 9-111), and HPV 18 GMT estimates were $127 \mathrm{IU} / \mathrm{mL}$ (95\% CI 88-185) vs. 16 IU/mL (95\% CI 5-49).

Among 15-26 year olds, HPV 16 GMT estimates for standard vs. single dose were $102 \mathrm{IU} / \mathrm{mL}$ (95\% CI 70-149) vs. $28 \mathrm{IU} / \mathrm{mL}$ (95\% CI 15-54) at 36 months, and 74 IU/mL (95\% CI 54-102) vs. 27 IU/mL (95\% CI 14-50) at 72 months. HPV 18 GMT estimates for standard vs. single dose were $66 \mathrm{IU} / \mathrm{mL}$ (95\% CI 44-98) vs. $21 \mathrm{IU} / \mathrm{mL}$ (95\% CI 12-39) at 36 months, and $50 \mathrm{IU} / \mathrm{mL}$ (95\% CI 37-69) vs. $24 \mathrm{IU} / \mathrm{mL}$ (95\% CI 13-42) at 72 months.

\subsubsection{Quadrivalent}

One study reported quadrivalent vaccine single dose data: Gilca 2019 (36- and 72-months, 9-14 years) [20]. Non-inferiority was not met for either HPV sub-type for any of the age groups or time points.

HPV 16 GMT estimates for standard vs. extended dose were 329 IU/mL (95\% CI 91-1189) vs. $18 \mathrm{IU} / \mathrm{mL}$ (95\% CI 3-102) at 36 months post-first dose, and $167 \mathrm{IU} / \mathrm{mL}$ (95\% CI 97-286) vs. $22 \mathrm{IU} / \mathrm{mL}$ (95\% CI 6-87) at 72 months. HPV 18 GMT estimates for standard vs. extended dose were $39 \mathrm{IU} / \mathrm{mL}$ (95\% CI 18-84) vs. $6 \mathrm{IU} / \mathrm{mL}$ (95\% CI 1-23) at 36 months post-first dose, and $15 \mathrm{IU} / \mathrm{mL}$ (95\% CI 8-28) vs. $8 \mathrm{IU} / \mathrm{mL}(95 \% \mathrm{CI} 2-32)$ at 72 months.

\subsubsection{Nonavalent}

No single dose data were available for the nonavalent vaccine.

\section{Discussion}

We analyzed data from 23 published studies comparing alternative dosing schedules (extended interval or single dose) to standard dosing schedules. Non-inferiority analyses showed mixed results based on dosing regimen, vaccine type, and time point. Our analysis utilized GMT levels as a correlate 
of protection. However, there is no established threshold of HPV titer that indicates protection; therefore, not meeting the non-inferiority criteria does not necessarily mean that the alternative schedules will not confer adequate protection against HPV 16 and 18 infection.

For extended interval analyses, non-inferiority was demonstrated for all three vaccines at multiple time points for both HPV 16 and HPV 18 titers, with the exception of HPV 16 titers of the bivalent vaccine at one month post-last dose and 36 months post-first dose, and HPV 16 titers for the quadrivalent vaccine one month post-last dose. Interestingly, Puthanakit et al. [29], one of the studies contributing to our analysis, found a non-inferior relationship between extended dose and standard schedules for the bivalent vaccine at one month post-last dose. This difference in findings from our own analysis is likely due to our pooling of results (six studies, including Puthanakit et al., contributed standard dose data for the bivalent, one-month extended interval analysis), which altered the comparison group, such as differing age structures. While Puthanakit et al. included ages 9-14, nearly half of the pooled comparison group came from a study that was restricted to ages 9-10 [22]. As younger participants often show higher immune responses, this may have resulted in a higher titer level among the pooled standard dose group as compared to the Puthanakit et al. analysis. The difference could also be due to random variation.

For single dose regimens, non-inferiority was not demonstrated for bivalent or quadrivalent vaccines at any time point in our studies. However, the data on single dose vaccinations were limited and none came from studies designed to assess single dose immunogenicity; all three included studies collected single dose data from participants who were supposed to receive 2 or 3 doses but failed to do so. As these individuals were not randomized to receive the single dose schedule, these results may not be generalizable to larger populations. In addition, as these data are from individuals who were supposed to receive additional doses, it was not possible to assess whether a single vaccination with a higher dose could confer a greater immunological response. There are a number of ongoing RCTs of single dose schedules that are attempting to answer these questions (see clinical trial registrations NCT03180034, NCT03675256, NCT03832049, and NCT02834637).

Our analysis suggests that extended interval dosing schedules may be an effective alternative for HPV vaccination. Under the current schedules, both the market availability and logistical hurdles make it difficult for countries to achieve high coverage. A 2016 systematic review of global HPV vaccine coverage found that coverage varies greatly by region and income level [43]. The review found that globally, 6.1\% of women aged 10-20 had received a full course of HPV vaccination. However, most vaccine recipients were from high-income countries, with $33.6 \%$ coverage in developed countries compared to $2.6 \%$ in developing countries. Africa and Asia both showed $1.2 \%$ vaccine coverage of this target demographic. If extended interval dosing provides similar amounts of protection as the currently recommended schedules, as our analysis suggests, this could improve vaccine coverage and reduce the barriers to access, especially in LMICs.

Extended interval and single dosing alternative schedules may provide several benefits. Single dose vaccination would decrease the cost of nationwide HPV vaccination programs, reducing logistics, supply chain, and staffing expenses. Eliminating or allowing for greater flexibility in the timing of the second dose would also decrease the programmatic challenges of vaccine delivery and reduce the burden on clients to attend clinic visits to complete the vaccine schedule. Extended interval dosing would also simplify school-based immunization programs, the most common venue for HPV vaccination in LMICs, therefore also reducing costs by allowing for annual rather than semi-annual school-based campaigns [44]. In response to the growing evidence base for alternative schedules, some policy changes are already being made, such as the recent WHO Strategic Advisory Group of Experts (SAGE) on Immunization advisory that states girls aged 9-10 can receive a two-dose schedule 3-5 years apart [45]. Further evidence, however, is required to inform more widespread changes to current HPV vaccination schedule policies. 


\section{Limitations}

The present meta-analysis is subject to a variety of limitations, the most salient of which is a lack of extended interval and single dose data for robust comparisons among HPV-seronegative girls and young women aged 9-26, stratified by vaccine type and time points for assessment of immune response. The lack of extended interval and single dose data in the published literature has several implications for the results of the meta-analysis that may limit the interpretability of the findings. First, relevant data were not available for each vaccine at each time point. For example, no extended interval data were available for two of the licensed vaccines at 72 months post-first dose; thus, the present meta-analysis does not address the long-term comparability of immune response with an extended interval schedule for those vaccines. Further, no extended interval data were available for the 15-26 age range, restricting the present analysis to ages 9-14 years. Single dose data had similar restrictions, with no short-term data and no data for the nonavalent vaccine. Finally, the non-inferiority analysis was based on measures of immunogenicity but not on efficacy. Without a standard titer threshold that correlates with protection, it is difficult to conclude if some of the inferior immunogenicity responses correlate to a lack of vaccine efficacy.

\section{Conclusions}

When evaluated against standard schedules, most extended interval analyses suggested that giving doses farther apart will confer non-inferior immune responses. Single doses did not meet criteria for non-inferiority in any comparisons. For both schedules, sparse data limited the number of possible comparisons. Given the possible large economic and health benefit of extended interval and single dose HPV vaccinations, further research is warranted.

Author Contributions: All authors have participated sufficiently in the work to take responsibility for the content, including participation in the conception or design of the work, or the acquisition, analysis or interpretation of data and drafting the work. A.M.S., M.D., B.K. and D.H. contributed to data collection and initial analysis. G.L. and R.V.B. contributed to analytic methods. P.K.D. provided project oversight. S.E.H., P.D. and P.K.D. provided technical review and expertise. As developed the structure of the article and wrote the first draft. All authors have read and agreed to the published version of the manuscript.

Funding: This research and the APC were funded by the Bill \& Melinda Gates Foundation (grant number OPP1155935).

Conflicts of Interest: The Bill \& Melinda Gates Foundation is also supporting clinical trials on single dose HPV vaccination. The authors do not have other competing interests.

Data Availability: The data that support the findings of this study are available from the corresponding author upon reasonable request.

\section{References}

1. Ferlay, J.; Shin, H.-R.; Bray, F.; Forman, D.; Mathers, C.; Parkin, D.M. Estimates of worldwide burden of cancer in 2008: GLOBOCAN 2008. Int. J. Cancer 2010, 127, 2893-2917. [CrossRef] [PubMed]

2. Arbyn, M.; Weiderpass, E.; Bruni, L.; De Sanjosé, S.; Saraiya, M.; Ferlay, J.; Bray, F. Estimates of incidence and mortality of cervical cancer in 2018: A worldwide analysis. Lancet Glob. Health 2020, 8, e191-e203. [CrossRef]

3. Burger, E.A.; Campos, N.G.; Sy, S.; Regan, C.; Kim, J.J. Health and economic benefits of single-dose HPV vaccination in a Gavi-eligible country. Vaccine 2018, 36, 4823-4829. [CrossRef] [PubMed]

4. Weaver, B.A. Epidemiology and natural history of HPV. J. Am. Osteopath. Assoc. 2006, 106, S2-S7.

5. Forman, D.; de Martel, C.; Lacey, C.J.; Soerjomatarama, I.; Lortet-Tieulent, J.; Bruni, L.; Vignat, J.; Ferlay, J.; Bray, F.; Plummer, M.; et al. Global burden of human papillomavirus and related diseases. Vaccine 2012, 30S, F12-F23. [CrossRef]

6. World Health Organization (WHO). Cervical Cancer [Internet]. Available online: https://www.who.int/ cancer/prevention/diagnosis-screening/cervical-cancer/en/ (accessed on 25 November 2019).

7. World Health Organization (WHO). Human papillomavirus vaccines: WHO position paper. Wkly. Epidemiol. Rec. 2017, 92, 241-268. 
8. Tan, N.; Sharma, M.; Winer, R.; Galloway, D.; Rees, H.; Barnabas, R. Model-estimated effectiveness of single dose 9-valent HPV vaccination for HIV-positive and HIV-negative females in South Africa. Vaccine 2018, 36, 4830-4836. [CrossRef]

9. Hu, Y.M.; Guo, M.; Li, C.G.; Chu, K.; He, W.G.; Zhang, J.; Gu, J.-X.; Li, J.; Zhao, H.; Wu, X.-H.; et al. Immunogenicity noninferiority study of 2 doses and 3 doses of an Escherichia coli-produced HPV bivalent vaccine in girls vs. 3 doses in young women. Sci. China Life Sci. 2020, 63, 582-591. [CrossRef]

10. Safaeian, M.; Sampson, J.N.; Pan, Y.; Porras, C.; Kemp, T.J.; Herrero, R.; Quint, W.; Van Doorn, L.-J.; Schussler, J.; Lowy, D.R.; et al. Durability of Protection Afforded by Fewer Doses of the HPV16/18 Vaccine: The CVT Trial. J. Natl. Cancer Inst. 2017, 110, 205-212. [CrossRef]

11. McInnes, M.D.F.; Moher, D.; Thombs, B.D.; McGrath, T.A.; Bossuyt, P.M.; Clifford, T.; Cohen, J.F.; Deeks, J.J.; Gatsonis, C.; Hooft, L.; et al. Preferred Reporting Items for a Systematic Review and Meta-analysis of Diagnostic Test Accuracy Studies The PRISMA-DTA Statement. Jama J. Am. Med. Assoc. 2018, 319, 388-396. [CrossRef]

12. Brown, D.; Müller, M.; Sehr, P.; Pawlita, M.; Seitz, H.; Rubio, I.; Antonello, J.; Radley, D.; Roberts, C.C.; Saah, A. Concordance assessment between a multiplexed competitive Luminex immunoassay, a multiplexed IgG Luminex immunoassay, and a pseudovirion-based neutralization assay for detection of human papillomaviruse types 16 and 18. Vaccine 2014, 32, 5880-5887. [CrossRef] [PubMed]

13. Pinto, L.A.; Wilkin, T.J.; Kemp, T.J.; Abrahamsen, M.; Isaacs-Soriano, K.; Pan, Y.; Webster-Cyriaque, J.; Palefsky, J.M.; Giuliano, A.R. Oral and systemic HPV antibody kinetics post-vaccination among HIV-positive and HIV-negative men. Vaccine 2019, 37, 2502-2510. [CrossRef] [PubMed]

14. Kjaer, S.K.; Sigurdsson, K.; Iversen, O.E.; Hernandez-Avila, M.; Wheeler, C.M.; Perez, G.; Brown, D.R.; Koutsky, L.A.; Tay, E.H.; García, P.; et al. A pooled analysis of continued prophylactic efficacy of quadrivalent human papillomavirus (types 6/11/16/18) vaccine against high-grade cervical and external genital lesions. Cancer Prev. Res. 2009, 2, 868-878. [CrossRef] [PubMed]

15. Garland, S.M.; Kjaer, S.K.; Muñoz, N.; Block, S.L.; Brown, D.R.; Dinubile, M.J.; Lindsay, B.R.; Kuter, B.J.; Perez, G.; Dominiak-Felden, G.; et al. Impact and effectiveness of the quadrivalent human papillomavirus vaccine: A systematic review of 10 years of real-world experience. Clin. Infect. Dis. 2016, 63, 519-527. [CrossRef] [PubMed]

16. Lehtinen, M.; Paavonen, J.; Wheeler, C.M.; Jaisamrarn, U.; Garland, S.M.; Castellsagué, X.; Skinner, S.R.; Apter, D.; Naud, P.; Salmerón, J.; et al. Overall efficacy of HPV-16/18 AS04-adjuvanted vaccine against grade 3 or greater cervical intraepithelial neoplasia: 4-year end-of-study analysis of the randomised, double-blind PATRICIA trial. Lancet Oncol. 2012, 13, 89-99. [CrossRef]

17. Hildesheim, A.; Wacholder, S.; Catteau, G.; Struyf, F.; Dubin, G.; Herrero, R. Efficacy of the HPV-16/18 vaccine: Final according to protocol results from the blinded phase of the randomized Costa Rica HPV-16/18 vaccine trial. Vaccine 2014, 32, 5087-5097. [CrossRef]

18. Joura, E.A.; Giuliano, A.R.; Iversen, O.E.; Bouchard, C.; Mao, C.; Mehlsen, J.; Moreira, E.D.; Ngan, Y.; Petersen, L.K.; Lazcano-Ponce, E.; et al. A 9-valent HPV vaccine against infection and intraepithelial neoplasia in women. N. Engl. J. Med. 2014, 372, 711-723. [CrossRef]

19. Vesikari, T.; Brodszki, N.; Van Damme, P.; Diez-Domingo, J.; Icardi, G.; Petersen, L.K.; Tran, C.; Thomas, S.; Luxembourg, A.; Baudin, M. A Randomized, Double-Blind, Phase III Study of the Immunogenicity and Safety of a 9-Valent Human Papillomavirus L1 Virus-Like Particle Vaccine (V503) Versus Gardasil ${ }^{\circledR}$ in 9-15-Year-Old Girls. Pediatr. Infect. Dis. J. 2015, 34, 992-998. [CrossRef]

20. Gilca, V.; Sauvageau, C.; Panicker, G.; De Serres, G.; Ouakki, M.; Unger, E.R. Antibody persistence after a single dose of quadrivalent HPV vaccine and the effect of a dose of nonavalent vaccine given 3-8 years later-An exploratory study. Hum. Vaccines Immunother. 2019, 15, 503-507. [CrossRef]

21. Sow, P.S.; Watson-Jones, D.; Kiviat, N.; Changalucha, J.; Mbaye, K.D.; Brown, J.; Bousso, K.; Kavishe, B.; Andreasen, A.; Toure, M.; et al. Safety and immunogenicity of human papillomavirus-16/18 AS04-adjuvanted vaccine: A randomized trial in 10-25-year-old HIV-seronegative African girls and young women. J. Infect. Dis. 2013, 207, 1753-1763. [CrossRef]

22. Lazcano-Ponce, E.; Stanley, M.; Muñoz, N.; Torres, L.; Cruz-Valdez, A.; Salmerón, J.; Rojas-Martínez, R.; Herrero, R.; Hernández-Ávila, M. Overcoming barriers to HPV vaccination: Non-inferiority of antibody response to human papillomavirus $16 / 18$ vaccine in adolescents vaccinated with a two-dose vs. a three-dose schedule at 21 months. Vaccine 2014, 32, 725-732. [CrossRef] [PubMed] 
23. Toh, Z.Q.; Russell, F.M.; Reyburn, R.; Fong, J.; Tuivaga, E.; Ratu, T.; Nguyen, C.D.; Devi, R.; Kama, M.; Matanitobua, S.; et al. Sustained antibody responses 6 years following 1, 2, or 3 doses of quadrivalent human papillomavirus (HPV) vaccine in adolescent fijian girls, and subsequent responses to a single dose of bivalent HPV vaccine: A prospective cohort study. Clin. Infect. Dis. 2017, 64, 852-859. [PubMed]

24. Sankaranarayanan, R.; Prabhu, P.R.; Pawlita, M.; Gheit, T.; Bhatla, N.; Muwonge, R.; Nene, B.M.; Esmy, P.O.; Joshi, S.; Poli, U.R.R.; et al. Immunogenicity and HPV infection after one, two, and three doses of quadrivalent HPV vaccine in girls in India: A multicentre prospective cohort study. Lancet Oncol. 2016, 17, 67-77. [CrossRef]

25. Hurt, L.; Nsouli-Maktabi, H.; Rohrbeck, P.; Clark, L. Use of Quadrivalent Human Papillomavirus Vaccine and the Prevalence of Antibodies to Vaccine-targeted Strains Among Female Service Members before and after Vaccination. Med. Surveill Mon. Rep. 2016, 23, 6-13.

26. Huang, L.M.; Puthanakit, T.; Cheng-Hsun, C.; Ren-Bin, T.; Schwarz, T.; Pellegrino, A.; Esposito, S.; Frenette, L.; McNeil, S.; Durando, P.; et al. Sustained immunogenicity of 2-dose human papillomavirus 16/18 AS04-adjuvanted vaccine schedules in girls aged 9-14 years: A randomized trial. J. Infect. Dis. 2017, 215, 1711-1719. [CrossRef] [PubMed]

27. Lamontagne, D.S.; Thiem, V.D.; Huong, V.M.; Tang, Y.; Neuzil, K.M. Immunogenicity of quadrivalent HPV vaccine among girls 11 to 13 years of age vaccinated using alternative dosing schedules: Results 29 to 32 months after third dose. J. Infect. Dis. 2013, 208, 1325-1334. [CrossRef]

28. Neuzil, K.M.; Canh, D.G.; Thiem, V.D.; Janmohamed, A.; Huong, V.M.; Tang, Y.; Diep, N.T.N.; Tsu, V.; Lamontagne, D.S. Immunogenicity and Reactogenicity of Alternative Schedules of HPV Vaccine in Vietnam. Jama J. Am. Med. Assoc. 2011, 305, 1424. [CrossRef]

29. Puthanakit, T.; Huang, L.M.; Chiu, C.H.; Tang, R.; Schwarz, T.F.; Esposito, S.; Frenette, L.; Giaquinto, C.; McNeil, S.; Rheault, P.; et al. Randomized open trial comparing 2-dose regimens of the human papillomavirus 16/18 as04-adjuvanted vaccine in girls aged 9-14 years versus a 3-dose regimen in women aged 15-25 years. J. Infect. Dis. 2016, 214, 525-536. [CrossRef]

30. LaMontagne, D.S.; Mugisha, E.; Pan, Y.; Kumakech, E.; Ssemaganda, A.; Kemp, T.J.; Cover, J.; Pinto, L.A.; Safaeian, M. Immunogenicity of bivalent HPV vaccine among partially vaccinated young adolescent girls in Uganda. Vaccine 2014, 32, 6303-6311. [CrossRef]

31. Brophy, J.; Bitnun, A.; Alimenti, A.; Lapointe, N.; Samson, L.; Read, S.; Karatzios, C.; Dobson, S.; Moses, E.; Blitz, S.; et al. Immunogenicity and safety of the quadrivalent human papillomavirus vaccine in girls living with HIV. Pediatr. Infect. Dis. J. 2018, 37, 595-597. [CrossRef]

32. Dobson, S.R.M.; McNeil, S.; Dionne, M.; Dawar, M.; Ogilvie, G.; Krajden, M.; Sauvageau, C.; Scheifele, D.W.; Kollmann, T.R.; Halperin, S.A.; et al. Immunogenicity of 2 doses of HPV vaccine in younger adolescents vs. 3 doses in young women: A randomized clinical trial. Jama J. Am. Med. Assoc. 2013, 309, 1793-1802. [CrossRef] [PubMed]

33. Herrin, D.M.; Coates, E.E.; Costner, P.J.; Kemp, T.J.; Nason, M.C.; Saharia, K.K.; Pan, Y.; Sarwar, U.N.; Holman, L.; Yamshchikov, G.; et al. Comparison of adaptive and innate immune responses induced by licensed vaccines for human papillomavirus. Hum. Vaccines Immunother. 2014, 10, 3446-3454. [CrossRef]

34. Iversen, O.E.; Miranda, M.J.; Ulied, A.; Soerdal, T.; Lazarus, E.; Chokephaibulkit, K.; Block, S.L.; Skrivanek, A.; Azurah, A.G.N.; Fong, S.M.; et al. Immunogenicity of the 9-valent HPV Vaccine Using 2-Dose Regimens in Girls and Boys vs. A 3-Dose Regimen in Women. Jama J. Am. Med. Assoc. 2016, 316, 2411-2421. [CrossRef] [PubMed]

35. Kim, Y.J.; Kim, K.T.; Kim, J.H.; Cha, S.; Kim, J.W.; Bae, D.S.; Nam, J.H.; Ahn, W.S.; Choi, H.S. Vaccination with a human papillomavirus (HPV)-16/18 AS04-adjuvanted cervical cancer vaccine in Korean girls aged 10-14 years. J. Korean Med. Sci. 2010, 25, 1197-1204. [CrossRef] [PubMed]

36. Lazcano-Ponce, E.; Torres-Ibarra, L.; Cruz-Valdez, A.; Salmerón, J.; Barrientos-Gutiérrez, T.; Prado-Galbarro, J.; Stanley, M.; Muñoz, N.; Herrero, R.; Hernández-Ávila, M. Persistence of immunity when using different human papillomavirus vaccination schedules and booster-dose effects 5 years after primary vaccination. J. Infect. Dis. 2019, 219, 41-49. [CrossRef] [PubMed]

37. Leung, T.F.; Liu, A.P.Y.; Lim, F.S.; Thollot, F.; Oh, H.M.L.; Lee, B.W.; Rombo, L.; Tan, N.C.; Rouzier, R.; Friel, D.; et al. Comparative immunogenicity and safety of human papillomavirus (HPV)-16/18 AS04-adjuvanted vaccine and HPV-6/11/16/18 vaccine administered according to 2- and 3-dose schedules in girls aged 9-14 years: Results to month 12 from a randomized trial. Hum. Vaccines Immunother. 2015, 11, 1689-1702. [CrossRef] [PubMed] 
38. Leung, T.F.; Liu, A.P.Y.; Lim, F.S.; Thollot, F.; Oh, H.M.L.; Lee, B.W.; Rombo, L.; Tan, N.C.; Rouzier, R.; De Simoni, S.; et al. Comparative immunogenicity and safety of human papillomavirus (HPV)-16/18 AS04-adjuvanted vaccine and 4vHPV vaccine administered according to two- or three-dose schedules in girls aged 9-14 years: Results to month 36 from a randomized trial. Vaccine 2018, 36, 98-106. [CrossRef]

39. Ogilvie, G.; Sauvageau, C.; Dionne, M.; McNeil, S.; Krajden, M.; Money, D.; Dobson, S. Immunogenicity of 2 vs. 3 Doses of the Quadrivalent Human Papillomavirus Vaccine in Girls Aged 9 to 13 Years after 60 Months. Jama J. Am. Med. Assoc. 2017, 317, 1687-1688. [CrossRef]

40. Petäjä, T.; Pedersen, C.; Poder, A.; Strauss, G.; Catteau, G.; Thomas, F.; Lehtinen, M.; Descamps, D. Long-term persistence of systemic and mucosal immune response to HPV-16/18 AS04-adjuvanted vaccine in preteen/adolescent girls and young women. Int. J. Cancer 2011, 129, 2147-2157. [CrossRef]

41. Schwarz, T.F.; Huang, L.M.; Medina, D.M.R.; Valencia, A.; Lin, T.Y.; Behre, U.; Catteau, G.; Thomas, F.; Descamps, D. Four-year follow-up of the immunogenicity and safety of the HPV-16/18 AS04-adjuvanted vaccine when administered to adolescent girls aged 1014 years. J. Adolesc. Health 2012, 50, 187-194. [CrossRef]

42. Schwarz, T.; Spaczynski, M.; Kaufmann, A.; Wysocki, J.; Gałaj, A.; Schulze, K.; Suryakiran, P.; Thomas, F.; Descamps, D. Persistence of immune responses to the HPV-16/18 AS04-adjuvanted vaccine in women aged 15-55 years and first-time modelling of antibody responses in mature women: Results from an open-label 6-year follow-up study. BJOG Int. J. Obs. Gynaecol. 2015, 122, 107-118. [CrossRef] [PubMed]

43. Bruni, L.; Diaz, M.; Barrionuevo-Rosas, L.; Herrero, R.; Bray, F.; Bosch, F.X.; Sanjose, S.; Castellsague, X. Global estimates of human papillomavirus vaccination coverage by region and income level: A pooled analysis. Lancet Glob. Health 2016, 4, e453-e463. [CrossRef]

44. Gallagher, K.E.; Howard, N.; Kabakama, S.; Mounier-Jack, S.; Burchett, H.E.D.; LaMontagne, D.S.; Watson-Jones, D. Human papillomavirus (HPV) vaccine coverage achievements in low and middle-income countries 2007-2016. Papillomavirus Res. 2017, 4, 72-78. [CrossRef] [PubMed]

45. World Health Organization (WHO). Weekly Epidemiological Record; World Health Organization (WHO): Geneva, Switzerland, 2019; Volume 47, pp. 541-560.

Publisher's Note: MDPI stays neutral with regard to jurisdictional claims in published maps and institutional affiliations.

(C) 2020 by the authors. Licensee MDPI, Basel, Switzerland. This article is an open access article distributed under the terms and conditions of the Creative Commons Attribution (CC BY) license (http://creativecommons.org/licenses/by/4.0/). 